\title{
Combination of Skid Control and Direct Yaw Moment Control to Improve the Safety and Stability of the Small Electric Vehicle with Two In-Wheel Motors
}

\author{
P.M. Heerwan ${ }^{1, *}$, S.M. Ashraf ${ }^{2}$, M.I. Ishak ${ }^{1}$ \\ ${ }^{1}$ Automotive Engineering Research Group (AERG), Faculty of Mechanical Engineering, University \\ Malaysia Pahang, 26600 Pekan, Pahang \\ ${ }^{2}$ Faculty of Mechanical Engineering, Universiti Malaysia Pahang, 26600 Pekan, Pahang
}

\begin{abstract}
For a small electric vehicle (EV) with the rear two in-wheel motors, the hydraulic brake system and the mechanical brake system are installed at the front and rear tire respectively. The mechanical brake system is used at the rear tire because there is no enough space for the hydraulic brake system. In a braking condition, the in-wheel motor at the rear tire will generate the regenerative braking force and it can improve the braking performance of the vehicle. However, during braking on the low adhesion road surface, anti-lock brake system (ABS) is very crucial to prevent the tire from lock-up. To improve the safety and stability of the vehicle, the combination of anti-skid control system and direct yaw moment control system is proposed. The anti-skid control system contains a hydraulic unit of ABS at the front tires and regenerative brake timing control at the rear tires. The control method of the regenerative brake timing control is same as ABS and it will turn on and off to prevent the tire from lock-up. On the other hand, the direct yaw moment control system is developed to increase the steer performance of the vehicle. The optimal control is used as the control strategy method to control the yaw moment. The simulation is developed in MATLAB Simulink and the result shows that the proposed model can improve the stopping distance from 9 seconds to 8.2 seconds. In addition, the combination of skid control and yaw moment control also improved the steer performance of the vehicle.
\end{abstract}

\section{Introduction}

Recently, research of the electrical vehicles (EVs) is become trending among automotive researchers [1]. It is because many advantages of EVs that can achieve than conventional internal combustion engine vehicles (ICEVs). One of the advantages of EV is the driving system, which is an electric motor is environmentally friendly and more easy to control than a combustion engine. There are several advantages of electric motor such as fast

\footnotetext{
*Corresponding author: mheerwan@ump.edu.my
} 
torque response, motor torque can be measured easily and the motor can be installed at each tire [2].

Although small EVs have many advantages, one of the challenges is the safety system. The small EVs only have the basic components of a safety system which is a seat belt and hydraulic-mechanical hybrid brake system (HMHBS). In the HMHBS, the hydraulic brake system is installed at the front tire and the mechanical brake system at the rear tire. The mechanical brake system is used at the rear tire because the space at the rear tire is not enough for the hydraulic brake system. Compared with the hydraulic brake system, the response performance of the mechanical brake system is lower than hydraulic brake system. The other challenges in the study to improve the safety of the small EVs are to engage the HMHBS with the anti-lock brake system (ABS). ABS is a basic skid control system to prevent the tire from lock-up and also can avoid the vehicle from skidding. The hydraulic unit of ABS cannot be installed at the rear tire because the space at the rear tire is very limited [3]. From the braking system of small EVs, it can be considered that the safety system needs to be improved.

S. Kobayashi et al have developed the simulation model of the hydraulicmechanical hybrid brake system (HMBS) with ABS to improve the braking performance of small EV [4]. In that study, the 3 hydraulic unit of ABS is engage with the HMHBS ; 2 hydraulic unit at each front tire, and one hydraulic unit is in between master cylinder and rear power cylinder. The result shows that during braking on an icy road, ABS only can prevent the front tire from lock-up. Although the hydraulic unit of ABS is install in between master cylinder and rear power cylinder, due to the low response performance of the mechanical brake system, the rear tire is lock-up.

M.Heerwan et al have improved the braking system of small EVs by using the inwheel motor. During braking, the in-wheel motor will generate the regenerative braking force. By using the same control method of ABS, the regenerative braking force timing control is developed [5]. The control method of the regenerative braking force timing control is similar with the ABS, which is based on the slip ratio of the tire. The result shows that by controlling the regenerative braking force, it can prevent the driving tire from lockup.

From the study of ABS and regenerative braking force timing control, the braking performance of small EVs with in-wheel motors can be improved. However, the steer performance of the small EVs also needs to be improved. During braking on the slippery road and at the same time the driver turns the steering wheel, the turning direction of the vehicle is not same as desired turning radius. This circumstance is occurred due to the low friction between the tire and road. M. Heerwan et al. have developed the HMBS with ABS at the front tire and regenerative brake timing control at the rear tire to improve the braking and steer performance on the cornering [6]. The result shows that HMBS with ABS and regenerative brake timing control also can improve the steer performance of the small EVs. Although that model can improve the steer performance, the stability of the vehicle is still need to be improved because the yaw rate is unstable.

In this paper, the combination of anti-skid control system and direct yaw moment control is proposed to increase the safety and stability of the small EVs. Anti-skid control system contains ABS and regenerative brake control. The hydraulic unit of ABS is installed at the front hydraulic brake system, while the regenerative brake timing control is used to control the braking force at the rear tire. In addition, for the direct yaw moment control, the optimal control method is used to improve the steer performance of the vehicle. The yaw moment from the linear model is compared to the non-linear model and feedback to the input, which is steer angle. The simulation model is developed in the MATLAB Simulink and the simulation result shows that the combination of anti-skid control system and direct yaw moment control system can increase the safety and stability of the small EVs. 


\section{Vehicle Model}

The Toyota Coms AK10E-PC is used as the vehicle analysis model. This vehicle employed in-wheel motors as a driving system. The capacity of the passenger is one person and the maximum speed is $50 \mathrm{~km} / \mathrm{h}$. Figure 1 shows the vehicle model and the specifications of the vehicle is shown in Table 1.

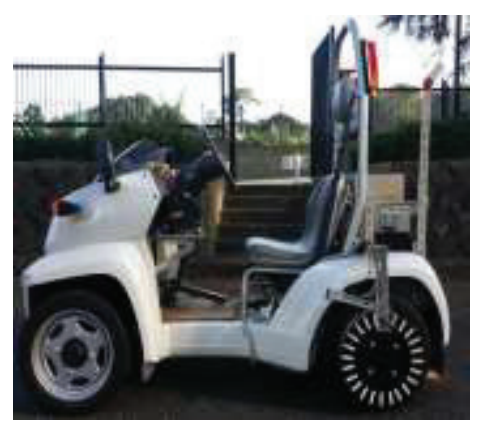

Fig 1. Analysis Vehicle Model, Toyota COMS, AK10E-PC

Table 1. Specifications of Toyota COMS

\begin{tabular}{|l|l|}
\hline Vehicle mass & $361.9(\mathrm{~kg})$ \\
\hline Maximum speed & $50(\mathrm{~km} / \mathrm{h})$ \\
\hline Height of center of gravity $(\mathrm{CoG})$ & $0.105(\mathrm{~m})$ \\
\hline Tread front & $0.840(\mathrm{~m})$ \\
\hline Tread rear & $0.815(\mathrm{~m})$ \\
\hline Wheel base & $1.280(\mathrm{~m})$ \\
\hline Inertia of front tire & $0.430\left(\mathrm{kgm}^{2}\right)$ \\
\hline Inertia of rear tire & $2.530\left(\mathrm{kgm}^{2}\right)$ \\
\hline Driving system & 2 in-wheel motors \\
\hline Motor power output & $0.290(\mathrm{~kW})$ \\
\hline Lead acid batteries & 6 sets, $12(\mathrm{~V}), 33(\mathrm{Ah})$ \\
\hline
\end{tabular}

\subsection{Braking system of the analysis vehicle model}

\subsubsection{Hydraulic-Mechanical Hybrid Brake System (HMHBS)}

The braking system of the analysis vehicle model is hydraulic-mechanical hybrid brake system (HMHBS) [3,4]. The hydraulic brake system is installed at the front tires, while the mechanical brake system is installed at the rear tires. Compared with the hydraulic brake system, due to the rigidness of the mechanical brake system, the response performance and the braking force of the mechanical braking system are lower than hydraulic brake system. 
Fig 2 shows the schematic diagram of the HMHBS. The components of HMHBS are master cylinder, front and rear brake tube, brake hose, front and rear wheel cylinder, power cylinder, link and wire. When the driver presses a brake pedal, the pressure of the brake fluid from the master cylinder is directed to the front wheel cylinder. However, for the mechanical brake system, the pressurised fluid from the master cylinder is directed to the rear power cylinder. Spring and damper in the rear power cylinder will generate the force and this force is transferred to the rear wheel cylinder by the link and wire.

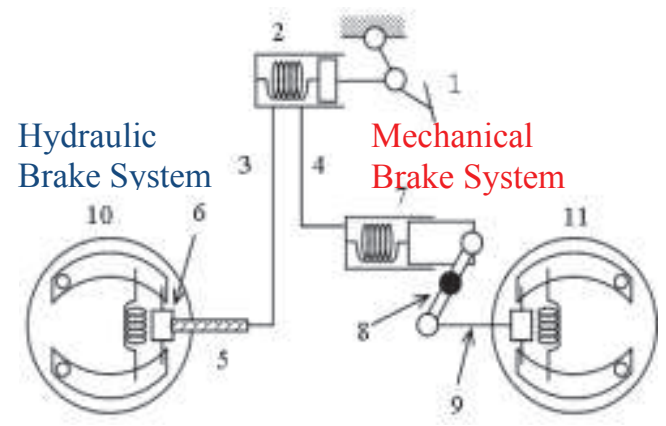

1:Brake Pedal; 2:Master Cylinder; 3:Front Brake Tube; 4:Rear Brake Tube; 5:Brake Hose; 6:Wheel Cylinder; 7:Power Cylinder; 8:Link ; 9:Wire; 10:Front Drum

Brake; 11:Rear Drum Brake

Fig 2 Schematic diagram of hydraulic-mechanical hybrid brake system

\subsubsection{Regenerative Brake System}

Fig 3 (a) and (b) shows how in-wheel motor works in a driving and braking condition respectively [10]. In the driving condition, the electrical energy from the battery will rotate the electric motor. In contrast, in the braking condition, the rotation of the tire will convert the kinetic energy into electrical energy and fed back to the battery. This mechanism is known as regenerative braking. Based on the mechanism, the regenerative braking force is proportional to the wheel speed. As a consequence, during braking the regenerative braking force will decrease according to the speed of the tire. Therefore, the regenerative brake system must work together with the mechanical brake system $[5,6]$.

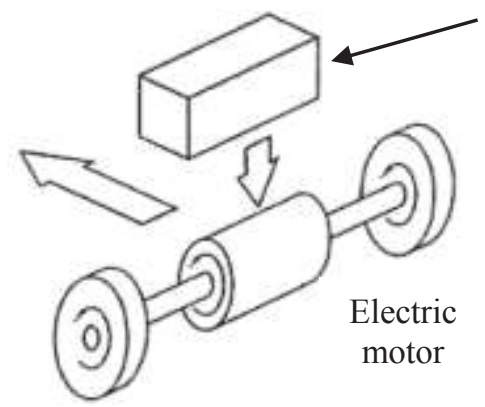

(a) In a driving condition

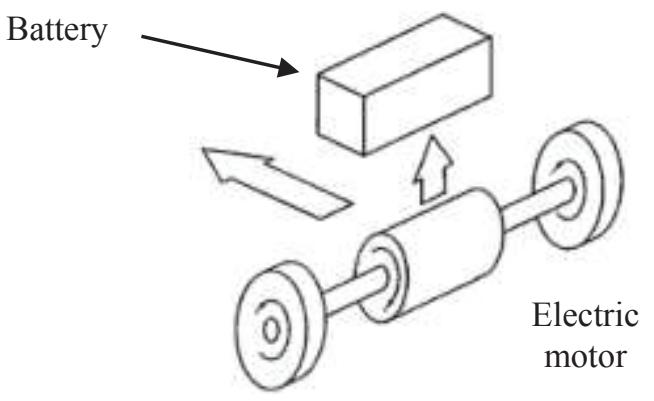

(b) In a braking condition

Fig 3 In-wheel motor at the rear tire 


\section{Control system method}

In this study, there are two control strategy methods; skid control to prevent the tire from lock-up and yaw moment control to improve the cornering performance. The effectiveness of the control model is developed in the MATLAB Simulink.

\subsection{Skid control}

Slip ratio is defined as the difference between the vehicle actual longitudinal velocity, $u$ and the rotational velocity of the tire, $r \omega$ [7]. In this study, the slip ratio is used as the control parameter to prevent the tire from lock-up. The equation of slip ratio is:

$$
\rho=u / r \omega
$$

Fig 5 shows the relation between friction coefficient and slip ratio at the dry asphalt and icy road [5-6]. From Fig 4, the optimum slip ratio at the icy road is 0.2 to 0.3 . In this optimum value, the friction between tire and road is maximum and the tire can grip at the road.

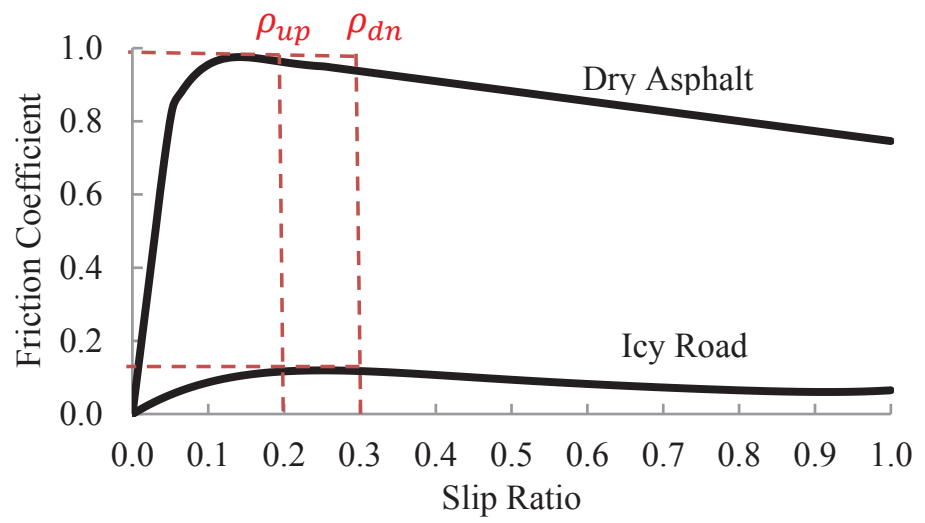

Fig 5 Relation between friction coefficient and slip ratio

\subsection{Direct yaw control}

In the direct yaw moment control (DYC), the two wheels of the linear vehicle model is used as an observer. The linear equations of motion are as below [8] :

$$
\begin{gathered}
\operatorname{mv} \dot{\beta}+2\left(\mathrm{~K}_{\mathrm{f}}+\mathrm{K}_{\mathrm{r}}\right) \beta+\left[\mathrm{mv}+\frac{2}{\mathrm{v}}\left(\mathrm{l}_{\mathrm{f}} \mathrm{K}_{\mathrm{f}}-\mathrm{l}_{\mathrm{r}} \mathrm{K}_{\mathrm{r}}\right)\right] \mathrm{r}=2 \mathrm{~K}_{\mathrm{f}} \delta \\
2\left(l_{f} K_{f}-l_{r} K_{r}\right) \beta+I \dot{\gamma}+\frac{2\left(l_{f}^{2} K_{f}+l_{r}^{2} K_{r}\right)}{v} r=2 l_{f} K_{f} \delta
\end{gathered}
$$

The cornering stiffness for the front and rear tire, $K_{f}$ and $K_{r}$ in equation (2) and equation (3) are the lateral force of the front and rear tire, $Y_{f}$ and $Y_{r}$ per unit side-slip angle of the front and the rear tire, $\beta_{f}$ and $\beta_{r}$. The equations of $K_{f}$ and $K_{r}$ are: 


$$
\begin{gathered}
K_{f}=\frac{\partial Y_{f}}{\partial \beta_{f}} \\
K_{r}=\frac{\partial Y_{r}}{\partial \beta_{r}}
\end{gathered}
$$

The state-space equation is used to describe a system in a linear motion.

$$
\dot{\mathrm{x}}=\mathrm{Ax}+\mathrm{bu}
$$

where,

$$
\begin{gathered}
\mathrm{A}=\left[\begin{array}{cc}
-\frac{2\left(K_{f}+K_{r}\right)}{m v} & -1-\frac{2\left(l_{f} K_{f}-l_{r} K_{r}\right)}{m v^{2}} \\
\frac{2}{I}\left(l_{f} K_{f}-l_{r} K_{r}\right) & -\frac{2\left(l_{f}{ }^{2} K_{f}+l_{r}{ }^{2} K_{r}\right)}{I v}
\end{array}\right] \\
\mathrm{x}=\left[\begin{array}{ll}
\beta & \gamma
\end{array}\right]^{T} \\
\mathrm{~b}=\left[\begin{array}{c}
\frac{2 K_{f}}{m v} \\
\frac{2 l_{f} K_{f}}{I}
\end{array}\right] \\
u=\delta
\end{gathered}
$$

Here, equation (7) and equation (9) can be simplified as:

$$
\begin{aligned}
\mathbf{A} & =\left[\begin{array}{ll}
a & b \\
c & d
\end{array}\right] \\
\mathbf{b} & =\left[\begin{array}{l}
e \\
f
\end{array}\right]
\end{aligned}
$$

In the state-space equation, $\mathrm{x}$ is a system state, $u$ is a scalar representing the input of the system and $\mathrm{y}$ is a scalar representing the output of the system. The matrixes $\mathrm{A}, \mathrm{b}$ and $\mathrm{c}$ determine the relationships between state and input and output variables [9]. In this system, the input of the system is steering angle, $\delta$.

To increase the steer performance of the vehicle, the feedback gain is added to the input, $u$ and the equation for input is:

where,

$$
u=-\mathrm{g}^{T} \mathrm{x}+\delta
$$

$$
\mathrm{g}=\left[\begin{array}{ll}
\mathrm{g}_{1} & \mathrm{~g}_{2}
\end{array}\right]^{T}
$$

Substituting equation (11) into equation (4), gives:

$$
\dot{x}=A x+b\left(-g^{T} x+\delta\right)
$$

where $\delta$ is a steering angle of the front tire. The block diagram of the state-space form in equation (15) is shown in Fig 6. 


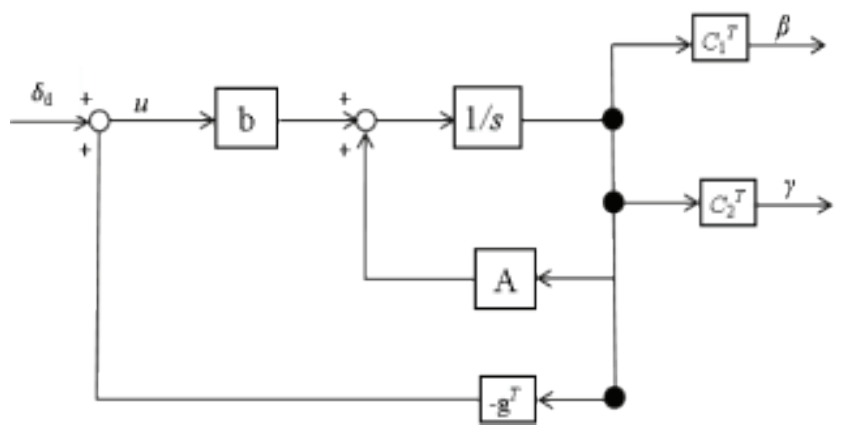

Fig 6 Block diagram of the state feedback control with the gain feedback to the input

In this study, the optimal control is used as a control strategy method in the observer. From equation (15), the evaluation function, $J$ is [11]:

where,

$$
J=\int_{0}^{\infty}\left(x^{T} \mathrm{Q} x+R \delta_{d}^{2}\right) d t
$$

$$
\mathrm{Q}=\left[\begin{array}{cc}
q_{11} & 0 \\
0 & q_{22}
\end{array}\right]
$$

Substitute equation (17) into equation (16) gives:

$$
J=\int_{0}^{\infty}\left(q_{11} \beta^{2}+q_{22} \gamma^{2}+R \delta_{d}^{2}\right) d t
$$

where $q_{11}, q_{22}$ and $R$ denote the state and input weighing matrixes.

Fig 7 shows block diagram of the state feedback control and gain with the non-linear system. The difference between yaw moment of the non-linear system with the yaw moment of the linear system is called as error. To eliminate the error, the weighting $H$ is introduced into the system. The state equation for the DYC with optimal control is as below:

$$
\dot{x}=A x+b\left(-g^{T} x+\delta\right)+H\left(\gamma_{\text {non-linear }}-\gamma\right)
$$

From equation (19), the gain is added to the input system to improve the steer angle, and the yaw angle can be improved by multiplying the error with the weighting, $H$. 


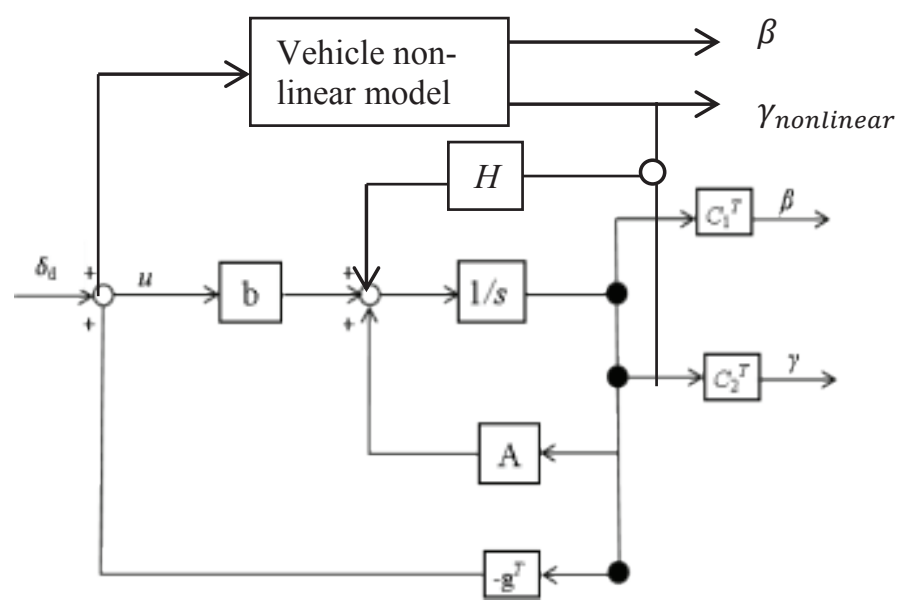

Fig 7 Block diagram of direct yaw moment control of non-linear model with linear model

\section{Results and discussion}

In the simulation, the road condition is set as an icy road and the steer angle is $15^{\circ}$. The initial speed of the vehicle is $30 \mathrm{~km} / \mathrm{h}$ and the braking pressure at the master cylinder is 1.8 $\mathrm{MPa}$.

\subsection{Speed of the vehicle and tires during braking without $A B S$ and regenerative brake control}

Fig 8 shows the velocity of the vehicle and the tires during braking on an icy road. The yaxis is speed in $\mathrm{m} / \mathrm{s}$ and the $\mathrm{x}$-axis is the time in $m \mathrm{~s}$. From this result, the stopping time of the vehicle, $u$ is $9.5 \mathrm{~s}$. The result also shows that the speed of the front tires, vFL and vFR are rapidly decreased to $0 \mathrm{~m} / \mathrm{s}$ in $0.3 \mathrm{~s}$. Without ABS control, the hydraulic braking force at the front tire is very large, and as a result, the tire is decreased rapidly. This phenomenon is called tire lock-up [3]. However, for the rear tires, vRL and vRR are decreased from 8.3 $\mathrm{m} / \mathrm{s}$ to $1.5 \mathrm{~m} / \mathrm{s}$ in $2 \mathrm{~s}$. From $2 \mathrm{~s}$ to $7 \mathrm{~s}, \mathrm{vRL}$ and vRR are constant at $1.5 \mathrm{~m} / \mathrm{s}$. Due to the inertia of the vehicle and slippery road condition, the vehicle will slide on the surface. In this situation, the rear tire will still rotate at a low speed. From this result, it is approved that during braking on a slippery road condition, without ABS the tire will lock up and the vehicle will skid. 


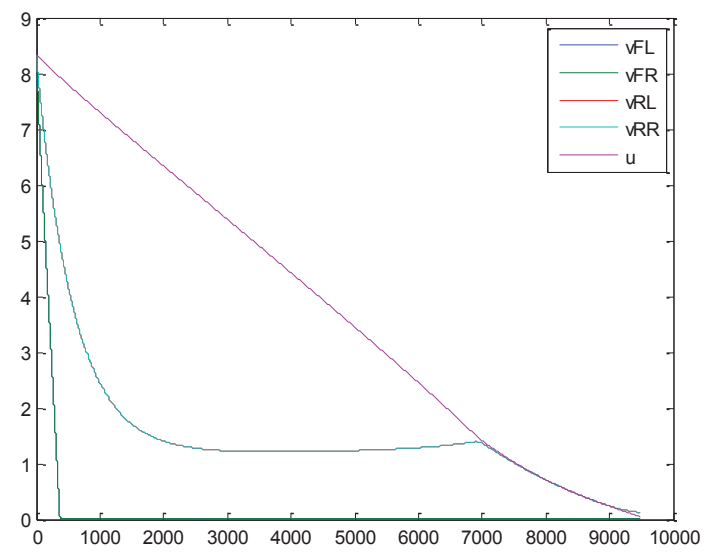

Fig 8 Speed of the vehicle and tires during braking without ABS, regenerative brake control and DYC

\subsection{Speed of the vehicle and tires during braking with combination control of $A B S$, regenerative brake control and DYC}

Figure 9 shows the speed of the vehicle, $u$, and the speed of the tires, vFL, vFR, vRL and vRR during braking on an icy road with ABS, regenerative brake control and DYC. From the result, the stopping time of the vehicle is improved to $8.2 \mathrm{~s}$. By using ABS and regenerative brake control, the speed of the front and rear tires are fluctuated and approach to the speed of the vehicle. When ABS is operational, the IN valve and OUT will open and close rapidly. Same mechanism as regenerative brake control, the in-wheel motor will on and off rapidly based on the slip ratio of the tire. From this mechanism, the speed of the tire are fluctuated and the tire lock-up can be prevented.

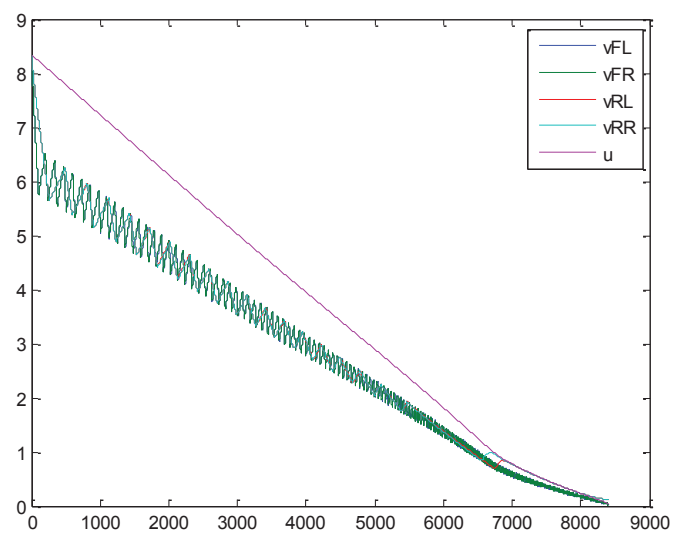

Fig 9 Speed of the vehicle and tires during braking with ABS, regenerative brake control and DYC 


\subsection{Steer performance of the vehicle during braking with combination control of ABS, regenerative brake control and DYC}

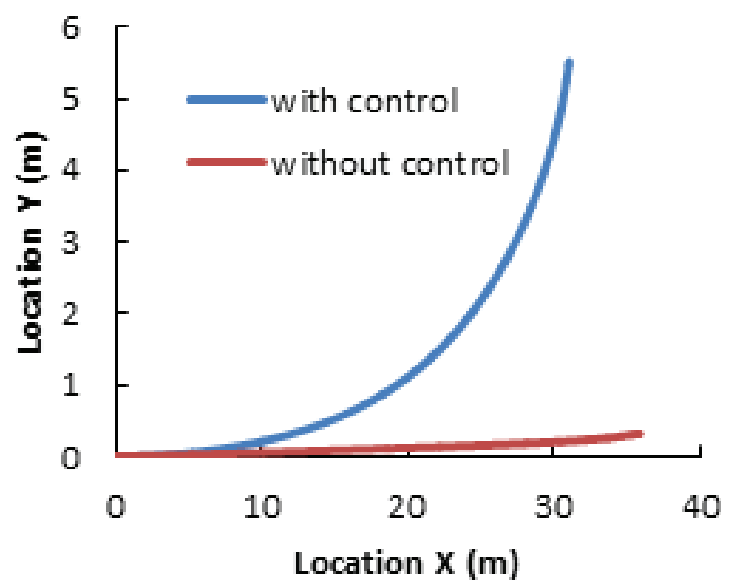

Fig 10 Trajectory of the vehicle during braking on an icy road

Fig 10 shows the trajectory of the vehicle during braking on an icy road. During braking without ABS, regenerative brake control and DYC, due to the low friction force between tire and road surface, the vehicle cannot be steered as driver desired. However, when the ABS, regenerative brake control and DYC are applied, the vehicle can be steered smoothly. ABS can regenerative brake control can increase the friction between the tire and road, and as result the tire will have more grip on the road surface. In addition, in the DYC, the yaw rate error between linear model and actual model is fed back to the steer angle to improve the steer performance of the vehicle. This result approved that the combination of ABS, regenerative brake control and DYC can prevent the vehicle from skidding and improve the steer performance of the vehicle.

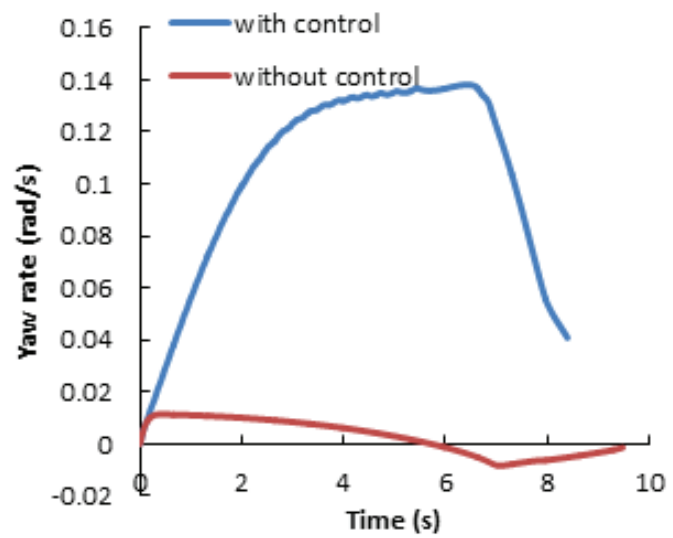

Fig 10 Yaw moment of the vehicle during braking on icy road 
The yaw moment of the vehicle during braking is shown in Fig 11. From Fig 11, the yaw moment of the vehicle when ABS, regenerative brake control and DYC applied is increased from 0 to $\mathrm{rad} / \mathrm{s}$ to $0.14 \mathrm{rad} / \mathrm{s}$. When the yaw rate increases, the turning radius of the vehicle also will increase. However, without ABS, regenerative brake control and DYC, the yaw moment of the vehicle is very small. This result approved that the proposed control system can improve the yaw rate of the vehicle.

\section{Conclusion}

In this paper, the combination of the anti-skid control system and direct yaw moment control are introduced to improve the safety and stability of the vehicle. The anti-skid control system contains ABS at the front tire and regenerative brake control at the rear tire. The direct yaw moment control is combined with the anti-skid control system to improve the stability and steer performance of the vehicle. From the result, the proposed control system can prevent the vehicle from skidding and also can increase the stability of the vehicle.

\section{Acknowledgments}

The authors would like to thank Universiti Malaysia Pahang (UMP) for providing laboratory facilities and financial assistance under project no. RDU160312. Special thanks to Ministry of Higher Education Malaysia for providing Research Acculturation Grant Scheme (RAGS) under project no RDU151403.

\section{References}

1. H. Mirzaeinejad and M. Mirzaei, Control Engineering Practice A novel method for non-linear control of wheel slip in anti-lock braking systems, Control Eng. Pract., Vol. 18, no. 8, pp. 918-926, (2010)

2. K. Fujii and H. Fujimoto, Traction control based on slip ratio estimation without detecting vehicle speed for electric vehicle, Proceedings of the 2007 Power Conversion Conference, pp.688-693, (2007)

3. S. Hasegawa and Ogino, H., Research on skid control of small electric vehicle with hydraulic-mechanical hybrid brake system ( $1^{\text {st }}$ Report: Simulation of 2 wheel model of anti-lock braking system), Proceedings of the School of Engineering, Tokai University, Vol.49, No.2, pp.89-94 (2009) (in Japanese)

4. S. Kobayashi and H. Ogino, Research on skid control of small electric vehicle with hydraulic-mechanical hybrid brake system (Simulation of 4 wheel brake model), Proceeding of the 2010 JSME Annual Congress (2010) (in Japanese)

5. M. Heerwan, H. Ogino, Y. Oshinoya, Skid control of a small electric vehicle with two in-wheel motors: Simulation model of ABS and regenerative brake control, International Journal of Crashworthiness, Vol 21, (2016)

6. M. Heerwan, H. Ogino, Y. Oshinoya, Skid control of a small electric vehicle with hydraulic-mechanical hybrid brake system (Effect of ABS and regenerative brake on an icy road), Mechanical Engineering Journal, Vol 5, (2014)

7. S. Sakai and Y. Hori, New skid avoidance method for electric vehicle with independently controlled 4 in-wheel motors, pp. 934-939 (1999)

8. W.Wang, L.Yuan, S.Tao,W.Zhang and T.Su, Estimation of vehicle side slip angle in 
nonlinear condition based on the state feedback observer, Proceedings of the 2010 IEEE International Conference on Automation and Logistics, pp. 632-636, (2010)

9. M. Heerwan, H. Ogino, Y. Oshinoya, Skid control of small electric vehicles (Direct yaw moment control using tire steer angle), Proceedings of School of Engineering, Tokai University, Vol. 39, (2014)

10. M.Ehsani, Y.Gao, S.E.Gay and A.Emadi, Modern electric, hybrid electric and fuel cell vehicles, Fundamentals, Theory and Design, CRC Press, Ltd., Boca Raton, Florida, (2003).

11. M.I.Ishak, H.Ogino, Y.Yamamoto, Numerical simulation analysis of an oversteer inwheel small electric vehicle integrated with four-wheel drive and independent steering, International Journal of Vehicular Technology, Vol. 2016, pp 1-12, (2016) 